\title{
ORIGINAL ARTICLE Intermittent energy restriction improves weight loss efficiency in obese men: the MATADOR study
}

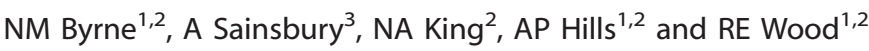

BACKGROUND/OBJECTIVES: The MATADOR (Minimising Adaptive Thermogenesis And Deactivating Obesity Rebound) study examined whether intermittent energy restriction (ER) improved weight loss efficiency compared with continuous ER and, if so, whether intermittent ER attenuated compensatory responses associated with ER.

SUBJECTS/METHODS: Fifty-one men with obesity were randomised to 16 weeks of either: (1) continuous (CON), or (2) intermittent (INT) ER completed as $8 \times 2$-week blocks of ER alternating with $7 \times 2$-week blocks of energy balance (30 weeks total). Forty-seven participants completed a 4-week baseline phase and commenced the intervention (CON: $N=23,39.4 \pm 6.8$ years, $111.1 \pm 9.1 \mathrm{~kg}$, $34.3 \pm 3.0 \mathrm{~kg} \mathrm{~m}^{-2}$; INT: $N=24,39.8 \pm 9.5$ years, $110.2 \pm 13.8 \mathrm{~kg}, 34.1 \pm 4.0 \mathrm{~kg} \mathrm{~m}^{-2}$ ). During ER, energy intake was equivalent to $67 \%$ of weight maintenance requirements in both groups. Body weight, fat mass (FM), fat-free mass (FFM) and resting energy expenditure (REE) were measured throughout the study.

RESULTS: For the $N=19$ CON and $N=17$ INT who completed the intervention per protocol, weight loss was greater for INT $(14.1 \pm 5.6$ vs $9.1 \pm 2.9 \mathrm{~kg} ; P<0.001)$. INT had greater FM loss $(12.3 \pm 4.8$ vs $8.0 \pm 4.2 \mathrm{~kg} ; P<0.01)$, but FFM loss was similar (INT: $1.8 \pm 1.6$ vs CON: $1.2 \pm 2.5 \mathrm{~kg} ; P=0.4$ ). Mean weight change during the $7 \times 2$-week INT energy balance blocks was minimal $(0.0 \pm 0.3 \mathrm{~kg})$. While reduction in absolute REE did not differ between groups (INT: $-502 \pm 481 \mathrm{vs}$ CON: $\left.-624 \pm 557 \mathrm{~kJ} \mathrm{~d}{ }^{-1} ; P=0.5\right)$, after adjusting for changes in body composition, it was significantly lower in INT (INT: $-360 \pm 502$ vs CON: $-749 \pm 498 \mathrm{~kJ} \mathrm{~d}^{-1}$; $P<0.05)$.

CONCLUSIONS: Greater weight and fat loss was achieved with intermittent ER. Interrupting ER with energy balance 'rest periods' may reduce compensatory metabolic responses and, in turn, improve weight loss efficiency.

International Journal of Obesity (2018) 42, 129-138; doi:10.1038/ijo.2017.206

\section{INTRODUCTION}

Part of the difficulty in losing weight and maintaining weight loss by lifestyle changes is that the body responds to energy restriction (ER) through a series of compensatory changes in biological and behavioural determinants of body weight. ${ }^{1,2}$ A key component of this is a reduction in resting energy expenditure (REE), which has been observed in lean rodents and humans during fasting and severe ER. ${ }^{3-5}$ Paradoxically, it is also seen in people with overweight or obesity after only modest weight loss, ${ }^{6-8}$ as we have outlined in a recent review. ${ }^{9}$

Given that REE is determined largely by body size and composition, it is expected to decrease with weight loss. However, during ER, REE has been reported to decrease to a greater extent than that expected from changes in body composition, a phenomenon termed 'adaptive thermogenesis'. ${ }^{10}$ This leads to markedly reduced efficiency of weight loss. For instance, we ${ }^{11}$ and others ${ }^{12,13}$ have shown that, at the onset of prolonged continuous ER interventions, actual weight loss was almost $100 \%$ of that expected from energetic calculations. However, as the period of continuous ER continues, weight loss per unit energy deficit was substantially reduced, and a large proportion of the less than expected weight loss could be explained by the reduction in REE. ${ }^{11}$ Therefore, finding ways to attenuate this adaptive decrease in REE during ER may improve weight loss and maintenance.
Although some studies of adults with overweight or obesity suggest that compensatory responses to ER and weight loss persist beyond the ER period, ${ }^{14-19}$ other research suggests that many of these responses can be reversed following a 7- to 14-day period of energy balance post-weight loss. ${ }^{1,20}$ This raises the possibility that periods of deliberate energy balance could be exploited during dietary interventions to enhance the efficiency of weight loss. This approach is akin to periodisation in exercise training programmes which incorporate stimulus cycles to progressively overload the physiology and stimulate positive adaptations in functional capacity, and cycles of reduced training volume designed to avoid overtraining and the negative effects on performance that result from chronically high training loads. ${ }^{21}$ In a similar way, an intermittent approach to ER, consisting of cycles of restriction interspersed with periods of energy balance, may attenuate compensatory responses associated with chronic $E R$, and thus provide a more effective and sustainable weight loss strategy than traditional continuous approaches.

We proposed that an optimal intermittent ER cycle might be to combine 2-week blocks of energy balance (sufficient time for the attenuation of adaptive thermogenesis) with ER blocks of the same length. The use of 2-week blocks of ER is based on analysis of the seminal Minnesota semi-starvation studies which revealed that the reduction in REE accompanying ER comprises two phases; a rapid, early phase $\left(\sim 2\right.$ weeks $\left.{ }^{22,23}\right)$ which is likely attributable to

\footnotetext{
${ }^{1}$ School of Health Sciences, Faculty of Health, University of Tasmania, Launceston, Tasmania, Australia; ${ }^{2}$ Queensland University of Technology, School of Exercise and Nutrition Sciences and Institute of Health and Biomedical Innovation, Brisbane, Queensland, Australia and ${ }^{3}$ The Boden Institute of Obesity, Nutrition, Exercise \& Eating Disorders, Sydney Medical School, Charles Perkins Centre, The University of Sydney, Camperdown New South Wales, Australia. Correspondence: Professor NM Byrne, School of Health Sciences, Faculty of Health, University of Tasmania, Newnham Campus, Launceston, Tasmania 7250, Australia.

E-mail: nuala.byrne@utas.edu.au

Received 3 March 2017; revised 2 July 2017; accepted 6 August 2017; accepted article preview online 17 August 2017; advance online publication, 19 September 2017
} 
alterations in processes regulating cellular metabolism in response to an acute change in energy balance, ${ }^{13,24-26}$ and a later phase where the reduction in REE is a function of reduced body tissue. ${ }^{27}$

Based on the above considerations, we examined the effect of repeatedly interrupting ER with deliberate periods of energy balance (intermittent ER), in terms of its effects on body weight, body composition and REE. We hypothesised that, compared with continuous ER, intermittent ER, delivered as alternating 2-week blocks of ER and energy balance, would result in more efficient weight and fat loss (greater loss per unit ER), and that the compensatory reduction in REE typically associated with continuous ER, would be attenuated.

\section{MATERIALS AND METHODS}

The MATADOR (Minimising Adaptive Thermogenesis And Deactivating Obesity Rebound) study was a single-centre, parallel-group, randomised controlled trial. The study was granted ethics approval through the University Human Research Ethics Committee at the Queensland University of Technology, Australia. Fifty-one males with obesity were recruited in cohorts and, after screening, were allocated to the continuous (CON) or intermittent (INT) ER interventions. Participants initially undertook a 4-week baseline (weight stabilisation) phase to determine energy needs and help them to accommodate to the study diet macronutrient composition, and then undertook 16 weeks of ER delivered as either: (1) CON: 16 weeks of continuous (daily) ER, or (2) INT: 16 weeks of ER as $8 \times 2$-week blocks of ER interspersed with $7 \times 2$-week blocks of energy balance (30 weeks total; please see study design in Supplementary Item 1). Both groups then completed an 8-week post-weight loss energy balance phase. Including the 4-week baseline, 16- or 30-week ER, and 8-week postweight loss energy balance phases, the total length of the intervention was 28 and 42 weeks for the CON and INT groups, respectively. Food was provided for each of these three phases (further details in the section Provision of diet, below). Participants were followed up after a 6-month free-living period.

\section{Eligibility criteria for participants}

Eligible participants were males aged 25-54 years, with a body mass index classified as obese (30-45 $\mathrm{kg} \mathrm{m}^{-2}$ ), weight-stable ( $\pm 2 \mathrm{~kg}$ for 6 months prior to participation) and sedentary ( $<60 \mathrm{~min}$ of structured moderate to vigorous intensity physical activity per week). Exclusion criteria are listed in Supplementary Item 2.

\section{Recruitment and screening strategies}

Supplementary Item 3 is a CONSORT diagram providing an overview of the flow of participants through the study. The three-step screening process to assess eligibility is detailed in Supplementary Item 4. After providing informed consent, participants were randomly assigned in a 1:1 ratio to either the CON or INT interventions. While it was not possible to blind participants or research staff to the assigned treatment groups, there was no discussion with the participants regarding the difference between the two interventions. As shown in the CONSORT diagram, 51 men were randomised and commenced the 4-week baseline weight stabilisation phase, 47 completed the baseline phase, 41 completed the ER phase (16 or 30 weeks, in the CON and INT groups, respectively), and 36 completed the ER phase per protocol, which was defined as completion of the assigned ER intervention (CON or INT) without weight gain while in restriction, and meeting assessment requirements up to and including Week16 ER.

\section{Determination of weight maintenance energy requirements}

Weight maintenance energy requirements were estimated for each participant by multiplying measured REE (detailed below) by an appropriate physical activity level based on self-reported work-time and leisure-time physical activity. Participants were prescribed an individualised diet (detailed below) designed to maintain weight stability, and were provided with an electronic weighing scale to self-record body weight at home. These weights were used to assess the adequacy of energy intake for weight maintenance, and to adjust energy intake as required. If participants gained or lost weight consistently over at least 3 days, they were provided with instructions on how to adjust the energy intake of the provided diet to maintain weight stability.

\section{Energy restriction interventions}

The study was designed so that the ER diet for participants in both groups was equivalent to $67 \%$ of individual weight maintenance energy requirements (that is, $33 \%$ reduction in energy intake). The energy intake prescription was adjusted to account for reductions in REE that were measured after every 4 weeks of ER, to ensure that participants remained in the same relative energy deficit throughout the study. Consequently, the absolute deficit $\left(\mathrm{kJ} \mathrm{d}^{-1}\right)$ decreased significantly over time $(P<0.001)$ in both groups, but did not differ between CON and INT groups $(P=0.49)$ : WK1-4ER: $-4142 \pm 442$ and $-4009 \pm 647 \mathrm{~kJ} \mathrm{~d}^{-1}$; WK5-8ER: $-3998 \pm 464$ and $-3885 \pm 538 \mathrm{~kJ} \mathrm{~d}^{-1}$; WK9-12ER: $-3902 \pm 505$ and $-3790 \pm 583 \mathrm{~kJ} \mathrm{~d}^{-1}$; WK13-16ER: $-3810 \pm 533$ and $-3740 \pm 444 \mathrm{~kJ} \mathrm{~d}^{-1}$. During the seven energy balance blocks in the INT group, participants were prescribed a diet providing $100 \%$ of weight maintenance energy requirements.

\section{Provision of diet}

Participants were provided with all main meals and morning and afternoon snacks for the duration of the study ( 28 or 42 weeks for the CON and INT interventions, respectively). Meals were prepared by a commercial kitchen under the direction of a dietician and delivered to the participants' homes each week. This 'base' diet supplied the majority of each participant's energy requirements. The remaining energy intake came from additional, discretionary items, chosen by individual participants in consultation with a researcher (REW). Inclusion of discretionary items in a long-term (24-month) dietary intervention has been shown to increase compliance. $^{28}$ The planned macronutrient distribution in both ER and energy balance diets was $25-30 \%$ of energy as fat, $15-20 \%$ as protein and $50-60 \%$ as carbohydrate. Participants were required to complete daily selfreport food diaries for the duration of the study ( 28 or 42 weeks for CON and INT groups, respectively). The completion of these diaries was required for participants to be considered compliant with the study requirements, but the data have not been analysed as a measure of dietary adherence.

\section{Overview of data collection}

As shown in Supplementary Item 1, weight, body composition and REE were measured at the start and end of the 4-week baseline phase, after every 4 weeks of ER, at weeks 1, 2, 4 and 8 of the 8-week post-ER energy balance phase, and at follow-up 6 months later. Resting energy expenditure is not reported for the post-ER energy balance and 6-month follow-up time points due to a large amount of missing data. During ER, measurements were taken after the same number of weeks of ER for both groups. For example, the Week 4 measurement was taken 4 weeks after baseline for the CON group, and 6 weeks after baseline for the INT group (that is, after the first $2 \times 2$-week blocks of ER separated by $1 \times 2$-week block of energy balance). As another example, the Week 8 measurement was taken 8 weeks after baseline for the CON group, and 14 weeks after baseline for the INT group (that is, after $4 \times 2$-week blocks of ER separated by $3 \times 2$-week blocks of energy balance). Measurements were included every 4 weeks during the ER intervention to provide information on the time course of responses, in addition to pre-post comparisons. All measurements during the ER intervention were taken during restriction in both groups. For the INT group, measurements were made at the end of a 2-week block of ER.

\section{Body height, weight and composition}

Height was measured to the nearest $0.1 \mathrm{~cm}$ using a Harpenden stadiometer (Holtain Ltd, Crosswell, UK). At each laboratory visit, body weight was measured to the nearest $0.1 \mathrm{~kg}$ using a calibrated digital scale, and body composition was calculated from body density measured by air displacement plethysmography (BOD POD, Life Measurement Inc., Concord, CA, USA). In addition to laboratory measurements of weight, all participants were provided with an electronic weighing scale (Model WW147A, Conair Australia, Pty Ltd, Terrey Hills, NSW, Australia), and asked to record body weight at least weekly during the study. These self-reported body weights were used to track progress throughout the study, and provide additional information on the time course of changes in weight in the periods between laboratory visits.

\section{Resting energy expenditure}

resting energy expenditure was measured using a ventilated hood system (TrueOne 2400 Metabolic System, ParvoMedics Inc, Sandy, UT, USA), which was calibrated before each measurement using standardised gases. All 
testing was conducted between 0600 and $0900 \mathrm{~h}$ after a minimum 10-h overnight fast. Participants arrived at the laboratory by car and were instructed to minimise physical activity prior to arrival. Testing was performed in a thermo-neutral environment with participants lying supine in a comfortable position, head on a pillow, and a transparent ventilated hood placed over their head. During the measurement period, participants were asked to remain as relaxed as possible without falling asleep, and instructed not to talk or fidget. To reduce boredom and prevent sleep, participants listened to quiet music throughout the measurement. $\mathrm{VO}_{2}$ and $\mathrm{VCO}_{2}$ were measured continuously for $30 \mathrm{~min}$. After discarding the first 10 mins of data, REE was calculated as the lowest consecutive 10-min average value, provided that the coefficient of variation within that $10-\mathrm{min}$ interval was $<5 \%$. Resting energy expenditure was calculated using the Weir equation. ${ }^{29}$

\section{Calculation of predicted REE, and of changes from baseline}

Given the contention regarding the best analytical approach to assess and define adaptive thermogenesis, ${ }^{30-38}$ we examined changes in REE using three approaches:

1. Comparing REE over the intervention after adjustment for changes in fat mass (FM) and fat free mass (FFM).

2. Comparing measured REE with REE predicted from the group-specific equations developed using regression analysis of baseline data (see details below)

3. Comparing measured REE with REE predicted from the reference equation published by Muller et al. $^{39}$

It has been suggested ${ }^{32}$ that the most appropriate analysis uses the study-specific regression equation derived from baseline data (REE, body composition, age, sex). As such, linear regression analyses were performed to develop prediction equations for REE from baseline data (group allocation, age, FM, FFM). Whereas age did not significantly explain any of the variance in REE, group allocation accounted for a significant proportion of variance in REE. Consequently, a separate equation was derived for CON and INT:

$$
\begin{aligned}
\mathrm{CON}: \operatorname{REE}\left(\mathrm{kJ} \mathrm{d}^{-1}\right)= & 93.60 \times \mathrm{FFM}(\mathrm{kg})+36.04 \times \mathrm{FM}(\mathrm{kg})+1184 \\
& {\left[R^{2}=0.54 ; P<0.01 ; \mathrm{RMSE}=545.4\right] }
\end{aligned}
$$

INT : $\operatorname{REE}\left(\mathrm{kJ} \mathrm{d}^{-1}\right)=54.92 \times \mathrm{FFM}(\mathrm{kg})+46.46 \times \mathrm{FM}(\mathrm{kg})+2821$

$$
\left[R^{2}=0.57 ; P<0.01 ; \mathrm{RMSE}=617.9\right]
$$

Given the relatively small, homogeneous sample in the present study, it could be argued that the resulting prediction equation may not be robust. ${ }^{35}$ To overcome this potential weakness, REE was also predicted from the equation developed by Muller et al..$^{39}$ on a larger, phenotypically similar cohort (body mass index $>30 \mathrm{kgm}^{-2} ; N=278$ ); where female $=0$, male $=1$ :

$$
\begin{aligned}
\operatorname{REE}\left(\mathrm{MJ} \mathrm{d}^{-1}\right)= & 0.05685 \times \mathrm{FFM}(\mathrm{kg})+0.04022 \times \mathrm{FM}(\mathrm{kg})+0.808 \times \mathrm{sex} \\
& -0.01402 \times \text { age }(\mathrm{y})+2.818\left[R^{2}=0.70 ; \operatorname{RMSE}=0.87\right]
\end{aligned}
$$

These equations were used to predict REE at baseline, and after 4, 8, 12 and 16 weeks of ER for the CON and INT groups separately. Changes in REE from baseline for measured and predicted values were then compared.

\section{Statistical analyses}

All analyses were performed using the STATA statistical software package Version 14.2 (Statacorp LLC, College Station, TX, USA). Data are reported as mean \pm standard deviation (s.d.) unless otherwise specified. Mixed model repeated measures analyses were employed to determine changes in outcome variables from baseline, and differences between the CON and INT groups accounting for covariates (FM, FFM, age) where appropriate. Linear regression analyses were used to examine relationships between REE and body composition. Differences were considered significant where $P<0.05$.

Data are reported for all randomised participants via intention-to-treat (ITT) analysis using the Last-Observation-Carried-Forward method, whereby the last available measurement for each participant at the time point prior to withdrawal from the study is retained for each missing time point thereafter in the analysis. The ITT analyses include every participant who was randomised according to randomised treatment assignment, ignoring level of compliance, protocol deviations and withdrawals. ${ }^{40}$ Consequently, the estimate of treatment effect from ITT analyses is generally conservative. As some participants dropped out during the baseline phase without participating in the ER interventions, analyses are also provided for the sub-samples of all participants who completed the baseline phase $(\mathrm{CON}=23$; INT $=24)$, and those who completed Week 16 of $E R(C O N=22 ; I N T=19)$. In this way, we are able to report on the effect of the interventions with the maximum sample at the end of each stage of the study as reported in the CONSORT diagram.

To examine the efficacy of the two interventions, analyses were provided for the cohort of participants who completed Week 16 of ER per protocol $(\mathrm{CON}=19 ; \mathrm{INT}=17)$. Finally, as not all participants were available at the 6-month follow-up, analyses are also provided for participants who completed Week 16 of ER per protocol and were available for measurements at the 8-week post-ER energy balance phase and 6-month follow-up (CON = 13; INT = 15).

The primary outcome variable for the study was weight loss, and the secondary outcome was REE. Over 16 weeks of ER, the energy deficit imposed by a $33 \%$ energy deficit would result in an estimated weight loss of $\sim 14 \mathrm{~kg}$ for a $110 \mathrm{~kg}$ male. However, we and others have found, in wellcontrolled medium-length (12-24 weeks) dietary restriction interventions, that weight loss is $60-70 \%$ of what is predicted from the ER imposed. ${ }^{9-11}$ As such, the expected weight loss during continuous ER would be $\sim 9 \mathrm{~kg}$. We tested the hypothesis that weight loss would be greater (higher loss per unit ER) with intermittent vs continuous ER, in part because of attenuation of adaptive thermogenesis (smaller reduction in REE) in response to intermittent ER.

Accounting for the expected variance in starting weight, we calculated that 34 participants (17 per group) would be required, at a statistical power of $0.8(a=0.05)$, to detect (two-tailed) a $\sim 5 \mathrm{~kg}$ greater weight loss from ER without adaptive thermogenesis (INT: $14 \mathrm{~kg}$ ) compared with weight loss during continuous ER inducing thermogenic compensation (CON: $9 \mathrm{~kg}$ ).

It was uncertain a priori the degree to which adaptive thermogenesis could be attenuated using the model of intermittent ER we employed. Body composition-adjusted REE has been shown to decrease by $\sim 400 \mathrm{~kJ} \mathrm{~d}^{-1}$ within 2 weeks of commencing moderate ER, and larger reductions have been reported in response to more severe and prolonged ER. ${ }^{11,13,18,26,41}$ We, and others, have shown the decrease in body composition-adjusted REE, even in response to severe ER, is completely reversed after 10-14 days of reinstating an energy balance diet. ${ }^{11,20,41}$ Consequently, 18 participants (9 per group) would be required at a statistical power of $0.8(a=0.05)$ to detect (two-tailed) a $400 \mathrm{~kJ} \mathrm{~d}^{-1}$ reduction in body composition-adjusted REE compared with no change. Given that REE was measured during ER for both groups, but the magnitude of adaptive thermogenesis was predicted to be modified by the 2-week blocks of energy balance in the INT intervention, we estimated the effect would be potentially halved. To detect a difference of this magnitude $\left(\sim 200 \mathrm{~kJ} \mathrm{~d}^{-1}\right)$, a cohort of 38 (19 per group) would be required (two-tailed) at a statistical power of $0.8(\alpha=0.05)$. Anticipating a 25\% dropout during the intensive intervention, we planned to recruit 50 participants (25 per group).

\section{RESULTS}

Baseline

The only variable in which the two groups differed at baseline was REE, and only in the subset of participants who completed the intervention, or who completed the intervention per protocol (Table 1). This difference was largely accounted for by group differences (non-significant) in FFM and FM in these reduced cohorts (data not reported). As shown in Figure $1 \mathrm{a}$, the change in body weight over the 4-week baseline for the total group $(n=47)$ was $-1.6 \pm 1.4 \mathrm{~kg}(-1.4 \pm 1.2 \%)$, and did not differ, on average, between the CON and INT groups. For the 47 participants with measures at the start and end of baseline, the change in REE was $-138 \pm 511 \mathrm{~kJ} \mathrm{~d}^{-1}(-1 \pm 6 \%)$. This change tended to be related to weight loss $(r=0.26, P=0.07)$. One participant lost $6.1 \mathrm{~kg}$ during the baseline phase because of an error in the calculation of prescribed energy intake. Excluding this participant's data, average changes in body weight $(-1.5 \pm 1.3 \mathrm{~kg} ;-1.3 \pm 1.1 \%)$ and in REE $\left(-125 \pm 511 \mathrm{~kJ} \mathrm{~d}^{-1} ;-1 \pm 6 \%\right)$ were not related $(r=0.22$, $P=0.13$ ). 
Table 1. Baseline characteristics presented with participants as randomised, completed baseline, completed intervention, completed intervention per protocol, and completed intervention per protocol and available for 6-month follow-up

\begin{tabular}{|c|c|c|c|c|}
\hline & $\begin{array}{l}\text { Continuous } \\
\text { Mean } \pm \text { s.d. }\end{array}$ & $\begin{array}{l}\text { Intermittent } \\
\text { Mean } \pm \text { s.d. }\end{array}$ & $\begin{array}{l}\text { Difference } \\
\text { Mean } \pm \text { s.e. }\end{array}$ & $P$ \\
\hline Randomised & $N=25$ & $N=26$ & & \\
\hline Age (years) & $39.3 \pm 6.6$ & $39.9 \pm 9.2$ & $0.6 \pm 2.2$ & 0.79 \\
\hline Height $(\mathrm{cm})$ & $180.6 \pm 5.9$ & $178.4 \pm 7.0$ & $2.2 \pm 1.8$ & 0.24 \\
\hline Weight (kg) & $111.6 \pm 10.0$ & $109.8 \pm 14.1$ & $1.8 \pm 3.4$ & 0.61 \\
\hline BMI $\left(\mathrm{kg} \mathrm{m}^{-2}\right)$ & $34.4 \pm 3.3$ & $34.6 \pm 4.2$ & $0.2 \pm 1.1$ & 0.87 \\
\hline Body fat (\%) & $38.9 \pm 5.2$ & $39.7 \pm 6.8$ & $0.8 \pm 1.7$ & 0.63 \\
\hline Fat mass (kg) & $43.6 \pm 8.5$ & $44.1 \pm 11.5$ & $0.5 \pm 2.9$ & 0.87 \\
\hline Fat-free mass $(\mathrm{kg})$ & $68.0 \pm 6.1$ & $65.7 \pm 7.4$ & $2.2 \pm 1.9$ & 0.25 \\
\hline $\begin{array}{l}\text { Resting energy } \\
\text { expenditure }\left(\mathrm{kJ} \mathrm{d} \mathrm{d}^{-1}\right)\end{array}$ & $9038 \pm 737^{\mathrm{a}}$ & $8619 \pm 963$ & $419 \pm 247$ & 0.1 \\
\hline Completed baseline & $N=23$ & $N=24$ & & \\
\hline Age (years) & $39.4 \pm 6.8$ & $39.8 \pm 9.5$ & $0.3 \pm 2.4$ & 0.89 \\
\hline Height $(\mathrm{cm})$ & $180.2 \pm 6.0$ & $178.7 \pm 7.2$ & $1.5 \pm 1.9$ & 0.44 \\
\hline Weight (kg) & $110.7 \pm 9.1$ & $110.1 \pm 13.8$ & $0.6 \pm 3.4$ & 0.86 \\
\hline BMI $\left(\mathrm{kg} \mathrm{m}^{-2}\right)$ & $34.3 \pm 3.0$ & $34.5 \pm 4.0$ & $0.3 \pm 1.0$ & 0.81 \\
\hline Body fat (\%) & $39.2 \pm 5.3$ & $39.8 \pm 6.4$ & $0.7 \pm 1.7$ & 0.7 \\
\hline Fat mass $(\mathrm{kg})$ & $43.6 \pm 8.6$ & $44.2 \pm 10.9$ & $0.6 \pm 2.9$ & 0.83 \\
\hline Fat-free mass (kg) & $67.1 \pm 5.2$ & $65.9 \pm 7.7$ & $1.2 \pm 1.9$ & 0.53 \\
\hline $\begin{array}{l}\text { Resting energy } \\
\text { expenditure }\left(\mathrm{kJ} \mathrm{d}^{-1}\right)\end{array}$ & $9038 \pm 737$ & $8585 \pm 941$ & $452 \pm 247$ & 0.07 \\
\hline $\begin{array}{l}\text { Completed } \\
\text { intervention (Wk16) }\end{array}$ & $N=22$ & $N=19$ & & \\
\hline Age (years) & $39.5 \pm 6.9$ & $39.5 \pm 9.1$ & $0.02 \pm 2.5$ & 0.99 \\
\hline Height $(\mathrm{cm})$ & $180.6 \pm 5.7$ & $178.0 \pm 7.4$ & $2.7 \pm 2.0$ & 0.2 \\
\hline Weight (kg) & $110.9 \pm 9.3$ & $108.0 \pm 12.7$ & $2.9 \pm 3.4$ & 0.41 \\
\hline BMI $\left(\mathrm{kg} \mathrm{m}^{-2}\right)$ & $34.1 \pm 3.0$ & $34.1 \pm 3.7$ & $0.02 \pm 1.1$ & 0.99 \\
\hline Body fat (\%) & $39.0 \pm 5.4$ & $39.9 \pm 6.8$ & $0.9 \pm 1.9$ & 0.64 \\
\hline Fat mass $(\mathrm{kg})$ & $43.5 \pm 8.8$ & $43.5 \pm 10.7$ & $0.1 \pm 3.0$ & 0.98 \\
\hline Fat-free mass $(\mathrm{kg})$ & $67.3 \pm 5.2$ & $64.5 \pm 7.8$ & $2.8 \pm 2.0$ & 0.18 \\
\hline $\begin{array}{l}\text { Resting energy } \\
\text { expenditure }\left(\mathrm{KJ} \mathrm{d}^{-1}\right)\end{array}$ & $9029 \pm 753$ & $8376 \pm 833$ & $653 \pm 247$ & 0.01 \\
\hline $\begin{array}{l}\text { Completed per } \\
\text { protocol (Wk16) }\end{array}$ & $N=19$ & $N=17$ & & \\
\hline Age (years) & $41.2 \pm 5.5$ & $39.5 \pm 8.4$ & $1.7 \pm 2.3$ & 0.46 \\
\hline Height $(\mathrm{cm})$ & $180.3 \pm 6.1$ & $177.8 \pm 7.7$ & $2.5 \pm 2.3$ & 0.28 \\
\hline Weight (kg) & $110.9 \pm 9.6$ & $107.7 \pm 13.3$ & $3.3 \pm 3.8$ & 0.39 \\
\hline BMI $\left(\mathrm{kg} \mathrm{m}^{-2}\right)$ & $34.3 \pm 3.0$ & $34.1 \pm 4.0$ & $0.2 \pm 1.2$ & 0.86 \\
\hline Body fat (\%) & $39.4 \pm 5.0$ & $39.7 \pm 7.1$ & $0.3 \pm 2.0$ & 0.89 \\
\hline Fat mass $(\mathrm{kg})$ & $43.9 \pm 8.4$ & $43.1 \pm 11.3$ & $0.9 \pm 3.3$ & 0.79 \\
\hline Fat-free mass (kg) & $67.0 \pm 5.3$ & $64.5 \pm 8.1$ & $2.4 \pm 2.2$ & 0.29 \\
\hline $\begin{array}{l}\text { Resting energy } \\
\text { expenditure }\left(\mathrm{kJ} \mathrm{d} \mathrm{d}^{-1}\right)\end{array}$ & $9038 \pm 762$ & $8364 \pm 875$ & $674 \pm 272$ & 0.02 \\
\hline $\begin{array}{l}\text { Completed per } \\
\text { protocol (Wk16) and } \\
6 \text {-month follow-up }\end{array}$ & $N=13$ & $N=15$ & & \\
\hline Age (years) & $40.0 \pm 5.2$ & $40.3 \pm 7.6$ & $0.3 \pm 0.8$ & 0.72 \\
\hline Height $(\mathrm{cm})$ & $180.4 \pm 5.6$ & $178.9 \pm 6.9$ & $1.6 \pm 0.7$ & 0.02 \\
\hline Weight (kg) & $110.2 \pm 9.3$ & $108.6 \pm 13.5$ & $1.6 \pm 4.5$ & 0.72 \\
\hline BMI $\left(\mathrm{kg} \mathrm{m}^{-2}\right)$ & $34.0 \pm 3.6$ & $34.0 \pm 4.3$ & $0.0 \pm 1.5$ & 0.98 \\
\hline Body fat (\%) & $38.3 \pm 5.4$ & $40.4 \pm 6.9$ & $2.2 \pm 2.4$ & 0.36 \\
\hline Fat mass (kg) & $42.5 \pm 8.9$ & $44.2 \pm 11.0$ & $1.7 \pm 3.8$ & 0.66 \\
\hline Fat-free mass (kg) & $67.7 \pm 4.8$ & $64.4 \pm 8.6$ & $3.3 \pm 2.7$ & 0.23 \\
\hline $\begin{array}{l}\text { Resting energy } \\
\text { expenditure }\left(\mathrm{kJ} \mathrm{d} \mathrm{d}^{-1}\right)\end{array}$ & $9075 \pm 892$ & $8519 \pm 804$ & $557 \pm 322$ & 0.09 \\
\hline
\end{tabular}

Abbreviation: $\mathrm{BMI}$, body mass index. ${ }^{\mathrm{a}} \mathrm{N}=23$ Continuous; REE unavailable for two participants (one due to undiagnosed sleep apnea and unable to remain awake during measurement; one did not adhere to pre-test instructions). Significant group differences are indicated by bolded and italicised text.
Intervention: pre vs post

Weight loss was significantly greater in the INT than CON group for each analysis approach (Table 2). Specifically, weight loss over the 16-week ER intervention in the INT group was $47 \%$ greater than that in the CON group when considering data for all participants randomised or who completed baseline, 58\% greater for those who completed the intervention, 53\% greater for those who completed the intervention per protocol, and $80 \%$ greater for the cohort who were available for the 6-month follow-up.

There was a significantly greater average loss of FM in the INT compared with CON group for those who completed the intervention, those who completed the intervention per protocol, and those who were available for follow-up $(P<0.01$ for each analysis), and a tendency towards significance in the ITT analysis $(P=0.09$; Table 2). Changes in FFM were small, and not different between groups in any analyses. The proportional changes of FM and FFM did not differ between groups; FM comprised $~ 87 \pm 21 \%$ of the weight lost.

The reduction in absolute REE at completion of Wk16 ER did not differ between groups, with average differences of $6 \pm 6 \%$ (CON: $7 \pm 6 \%$; INT: $6 \pm 5 \%$ ) from end of baseline to Wk16ER. However, given the marked difference in weight loss between groups, after adjusting for changes in body composition, the reduction in REE was significantly smaller in INT $(4 \pm 6 \%)$ than in CON $(9 \pm 6 \%)$, and this was evident for both ITT and completers analyses (Table 2).

\section{Intervention: time course of responses}

The change in weight from the end of baseline was significant throughout ER for both groups, and cumulative weight loss was significantly greater in INT than CON from Wk8ER onwards (Figure 1a). Importantly, the weight change during the $7 \times 2$-week energy balance blocks in the INT group was, on average, $0.0 \pm 0.3 \mathrm{~kg}$ (Figure 1b). Supplementary Item 5 shows the magnitude of weight loss for every 4 weeks of ER. FM was significantly lower than baseline at each time point during the ER intervention for the INT group, whereas the reduction plateaued by $\mathrm{Wk} 12 \mathrm{ER}$ in the CON group (Figure 2).

The INT group had a greater initial decrease in absolute REE compared with CON (Figure 3a). However, the reduction in REE was similar between groups at Wk16ER, despite the greater reduction in body weight in INT. When adjusted for body composition, REE in CON decreased progressively across the intervention. In contrast, the initial decrease in REE in INT was partly reversed during the final 4 weeks of $E R$, resulting in a significantly lower reduction in REE than CON at Wk16ER (Figure 3b). Using the prediction equations derived at baseline, measured REE was significantly lower than predicted in CON at Wk16ER (Figure 3c), but tended to be higher than predicted at Wk16ER in INT (Figure 3d). Compared with REE predicted from the equation of Muller et al., ${ }^{37}$ the measured change in REE in the CON group was similar to predicted REE at Wk4ER and Wk8ER, but decreased to a greater extent than predicted from Wk12ER onwards (Figure 3e). In contrast, measured change in REE in the INT group was lower than predicted at Wk4ER but similar to predicted thereafter (Figure $3 \mathrm{f}$ ).

Intervention: 8-week post-weight loss energy balance and 6-month follow-up

A subset of the cohort $(\mathrm{CON}=13$, INT $=15)$ was available for body weight and composition measures during the 8-week post-weight loss energy balance phase and at the 6-month free-living followup. The weight change from the start of baseline to Wk16ER in this subset (Figure 4a: CON: $-10.1 \pm 3.7 \mathrm{~kg}$; INT: $-15.4 \pm 5.6 \mathrm{~kg}$ ) was similar to that in the larger cohort who completed the ER intervention (Figure 1). Weight was stable in INT throughout the 8 -week post-weight loss energy balance phase. Weight was also 
a

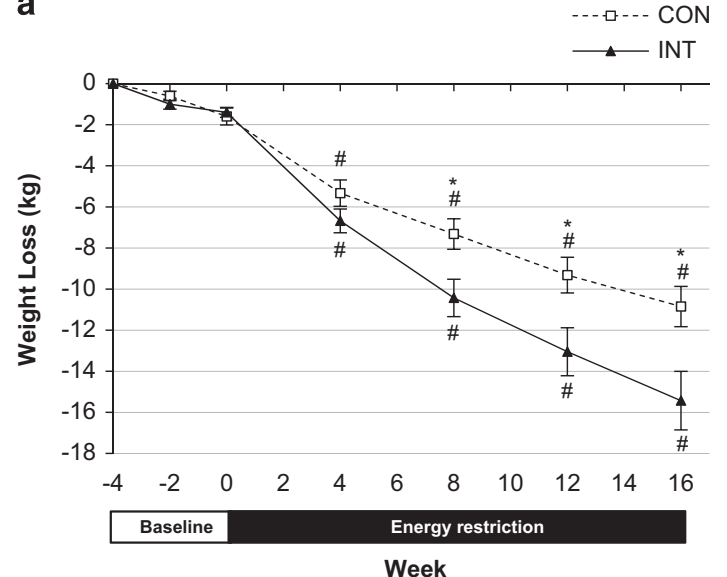

b

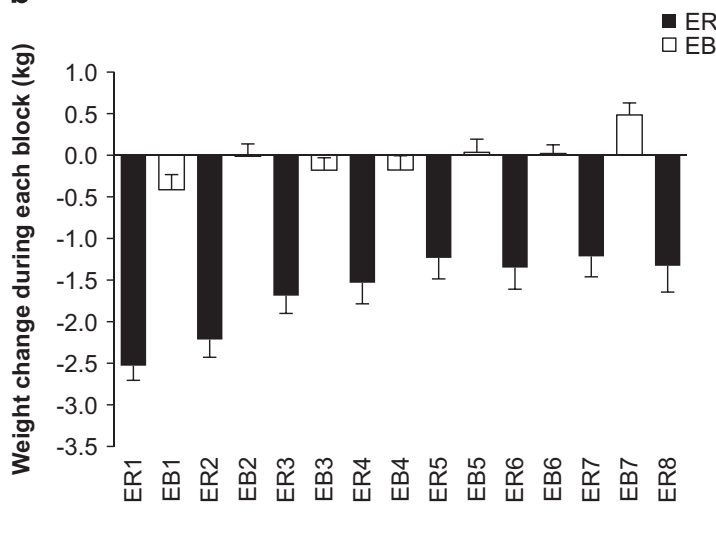

Figure 1. Changes in body weight ( $\mathrm{kg}$; mean \pm s.e.m.) during baseline and 16 weeks of energy restriction (ER) in the continuous (CON; $N=19)$ and intermittent (INT; $N=17)$ groups. (a) Cumulative weight change $(\mathrm{kg})$ over baseline $(-4,-2,0$ weeks) and after $4,8,12$ and 16 weeks of ER for the CON and INT groups. *Significant difference between groups; $P<0.05$. "Significant difference from baseline within-group; $P<0.01$. (b) Weight change (kg; mean \pm s.e.m.) in the intermittent energy restriction (INT) group during each of the $8 \times 2$-week energy restriction (ER) and $7 \times 2$-week energy balance $(E B)$ blocks that comprised the 30-week intervention. Data are from participant-reported weights measured at home ( $N=20$ except $N=19$ for ER5, EB5, EB6, ER7 and EB7, and $N=17$ for ER8). Weight change is calculated as the difference in weight measured from Day 1 of one block (for example, ER1) to Day 1 of the subsequent block (for example, EB1). Participants were instructed to record weight daily throughout the study. The majority ( $80 \%$ or $256 / 312)$ of measurements were taken on Day 1 of the block (as instructed), and $93 \%$ (299/312) of measurements were taken within \pm 1 day of Day 1.

stable in the CON group for the first 2 weeks of this phase, with subsequent small, but significant, increases of $0.6 \pm 1.3 \mathrm{~kg}$ at Wk4 and $1.2 \pm 2.1 \mathrm{~kg}$ at Wk8 (Weeks 20 and 24 in Figure 4a).

Weight regain over the 6-month post-intervention phase varied between individuals. On average, both groups regained weight over the 6-month follow-up (INT: $3.5 \pm 5.9$ vs CON: $5.9 \pm 4.7 \mathrm{~kg}$; $P=0.24$ ), but the total weight lost from the end of baseline remained greater in the INT group at follow-up (INT: $-11.1 \pm 7.4$ vs CON: $-3.0 \pm 4.4 \mathrm{~kg}, P=0.001)$. FM at the 6-month follow-up remained significantly lower than baseline in INT, but was not significantly different from baseline in CON (Figure 4b). The changes in FM were $4.9 \pm 3.9$ and $2.9 \pm 5.6 \mathrm{~kg}$, and in FFM were $1.0 \pm 1.9$ and $0.6 \pm 0.9 \mathrm{~kg}$ for CON and INT, respectively.

\section{DISCUSSION}

The aim of this investigation was to compare changes in body weight, body composition, and REE in men with obesity in response to: (1) 16 weeks of continuous ER, or (2) an equivalent duration and magnitude of ER delivered intermittently as alternating 2-week blocks of ER and energy balance. In support of the hypotheses, intermittent ER resulted in greater weight loss and greater (or a tendency for greater) fat loss, without greater loss of FFM, than an equivalent 'dose' of continuous ER. In addition, despite greater weight loss, there was a significantly smaller reduction in REE (adjusted for changes in FM and FFM) in the INT than in the CON group, consistent with attenuation of adaptive thermogenesis. Furthermore, although both groups regained weight post-intervention, weight loss (reduction from baseline) was, on average, $8.1 \mathrm{~kg}$ greater in the INT than CON group at the 6-month follow-up.

The superior weight loss in the INT group in the present study is in contrast with the majority of studies that have reported no advantage of intermittent over continuous ER. The term 'intermittent energy restriction' has become almost synonymous with the term 'intermittent fasting', which consists of alternating 1- to 7-day periods of complete or partial food restriction (true or modified fasting), and ad libitum food consumption. ${ }^{9}$ A recent 12 -month clinical trial ${ }^{42}$ and several recent reviews ${ }^{9,43,44}$ have concluded that existing models of intermittent ER (largely versions of intermittent fasting), could be considered equivalent, but not superior, alternatives for weight loss.

The intermittent approach in the present study differs fundamentally from intermittent fasting. In intermittent fasting paradigms, weight loss occurs over time if energy intake during ad libitum feeding periods is not sufficient to compensate for the substantially reduced energy intake on 'fasting' days. ${ }^{45}$ In contrast, energy intake was prescribed in both the ER and energy balance blocks in the present study, to create distinct periods of weight loss and maintenance. Given that this is the first application of an intermittent model using 2:2-week blocks of ER and energy balance, direct comparisons with other studies are not possible. However, previous studies that have compared continuous ER with intermittent approaches using ratios of ER to energy balance of 5:5-weeks over 25 weeks $^{46}$ or 1:1-week over 8 weeks ${ }^{47}$ have reported no advantage of intermittent ER (although the energy deficit in the latter study was not matched between groups). In addition, weight loss was not different following 14 weeks of continuous ER, and 14 weeks of ER interrupted by either a single 6 -week break or $3 \times 2$-week breaks of ad libitum intake. ${ }^{48}$ Given these findings, it is interesting to consider possible reasons for the superior weight loss in the INT vs CON group in the present study, in which both groups were exposed to the same 'dose' of ER.

Importantly, the average weight change (a proxy measure of energy balance) during the seven energy balance blocks in the INT group was only $0.0 \pm 0.3 \mathrm{~kg}$. Therefore, the greater weight loss in the INT group can be attributed to a higher rate of weight loss during the $8 \times 2$-week ER blocks, and not simply continual weight loss over a longer (30-week) intervention period. Indeed, it is possible that the attainment of energy balance during the 'breaks' from ER may be critical to the success of this approach. Allowing relatively uncontrolled or ad libitum feeding during the 'breaks' from ER often results in a hyperphagic response which may compromise weight loss. ${ }^{41,49}$ On the other hand, simply alternating between different levels of energy intake (while still maintaining a degree of ER) during a dietary intervention appears to be no more effective than using a continuous fixed level of ER. ${ }^{50,51}$ As such, incorporating periods of controlled energy balance, not simply variations in energy intake, may be necessary to realise the beneficial effects of intermittent ER. 
Table 2. Changes in weight, body composition and resting energy expenditure over the16-week intervention (from end of baseline to Week 16 of Energy Restriction) based on intention-to-treat (ITT) and completers analyses

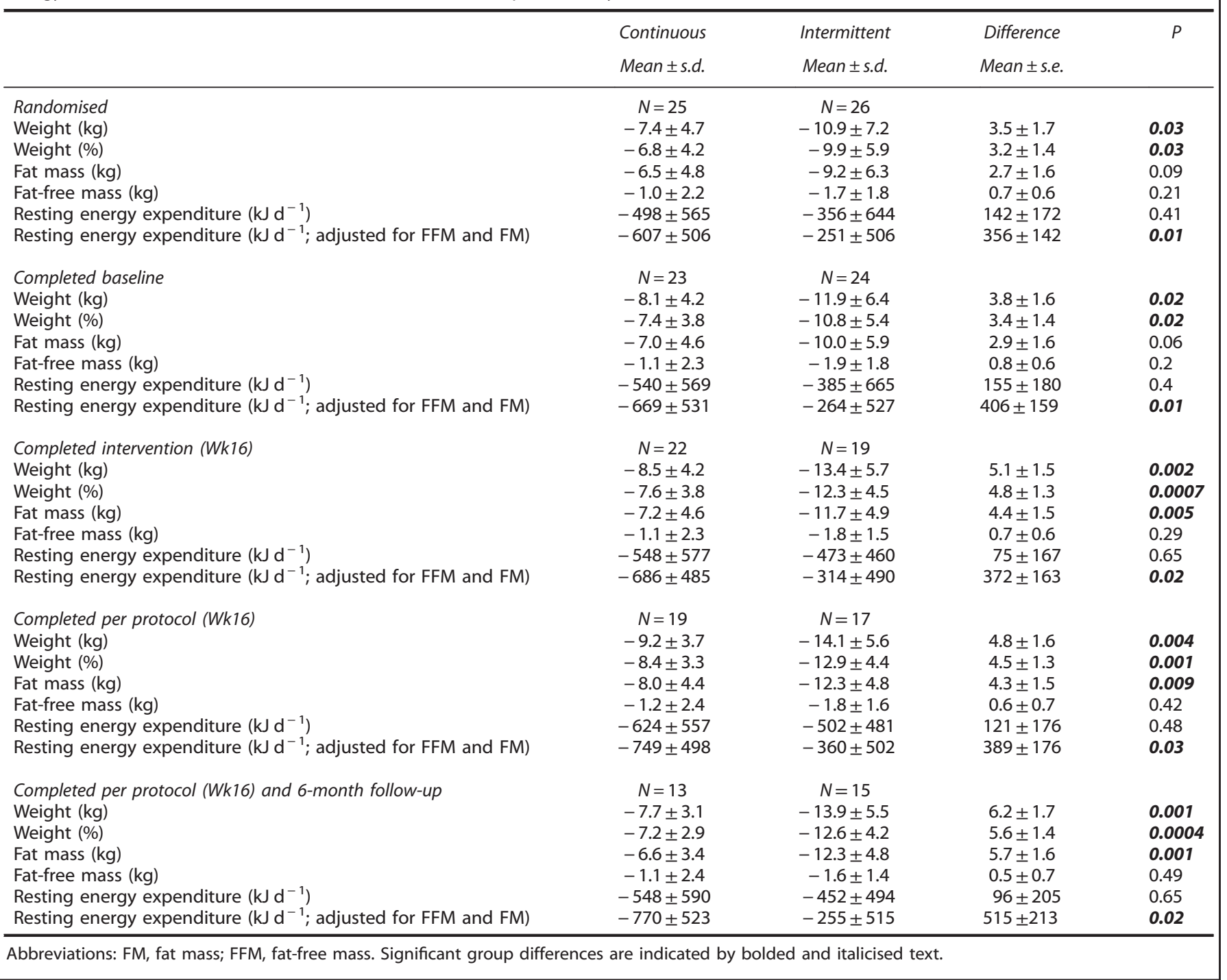

a

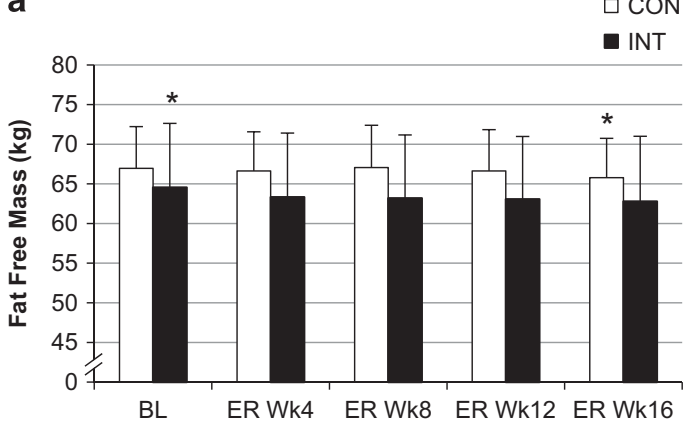

b

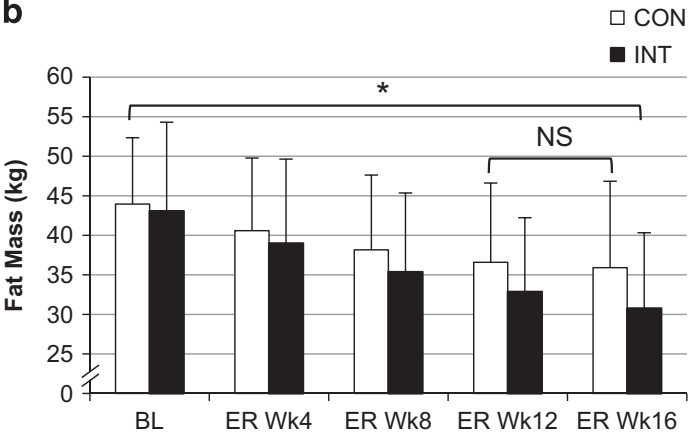

Figure 2. Fat-free mass (FFM) and fat mass (FM) at baseline and during 16 weeks of energy restriction (ER) for the continuous (CON; $N=19$ ) and intermittent (INT; $N=17)$ groups. (a) Fat-free mass $\left(\mathrm{kg} ;\right.$ mean $\pm \mathrm{s} . \mathrm{d}$.). ${ }^{*}$ Differs significantly $(P<0.05)$ from all other time points for the same intervention group. (b) Fat mass $(\mathrm{kg}$; mean \pm s.d.). *All time points differ significantly $(P<0.001)$ from each other within the same intervention group except those indicated (NS) in CON; these time points do not differ significantly $(P>0.05)$.

We hypothesised that intermittent ER would attenuate the decrease in REE. In support of this hypothesis, REE (adjusted for FM and FFM) decreased to a lesser extent in the INT group such that it was $\sim 377 \mathrm{~kJ} \mathrm{~d}^{-1}$ lower in the CON than INT group at
Wk16ER. This is consistent with the 2-week blocks of energy balance functioning as 'metabolic rest periods', attenuating the compensatory reduction in REE associated with continuous ER. There is scant evidence on changes in REE with intermittent $E R^{9}$ 


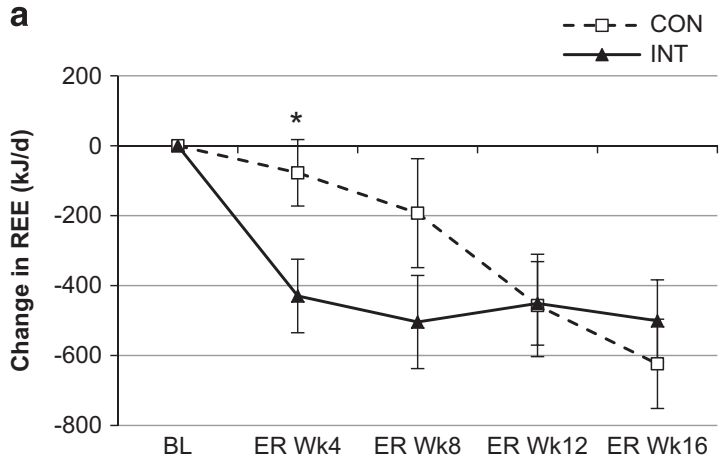

C
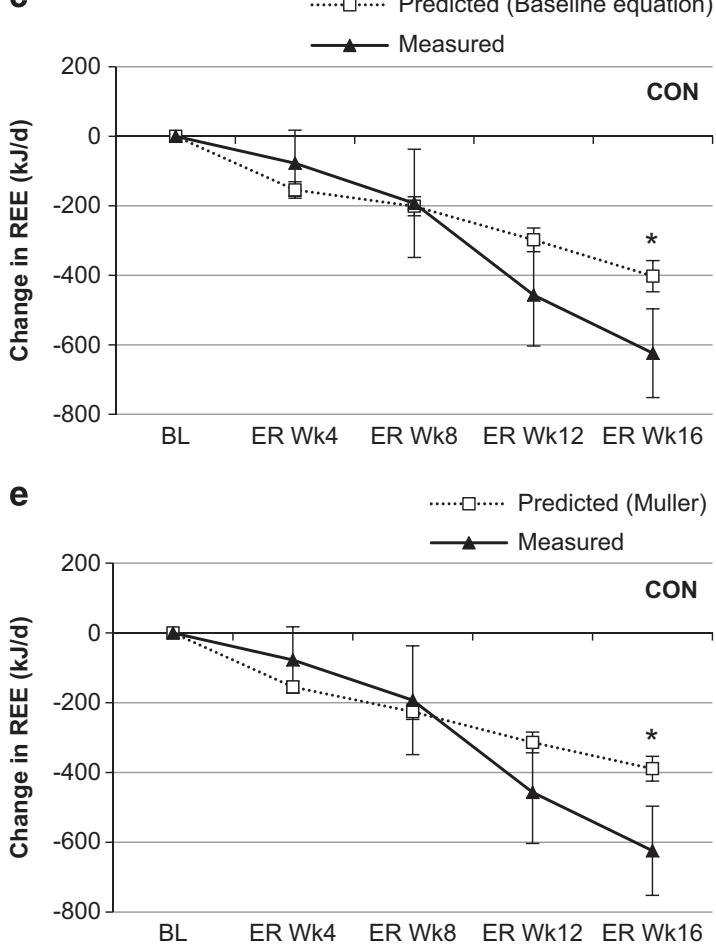

b

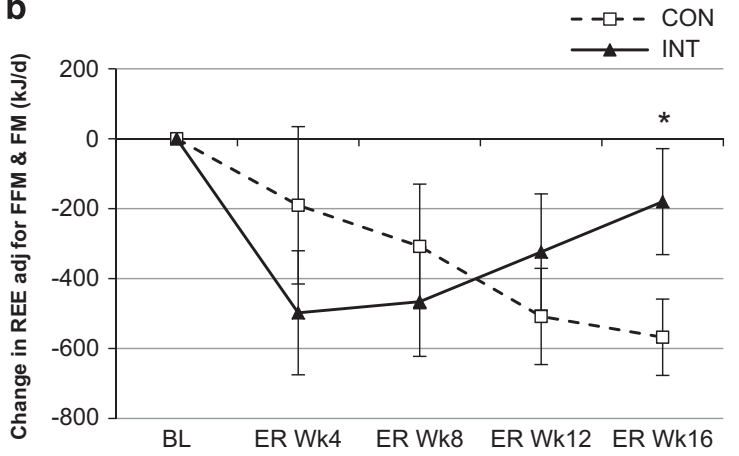

d

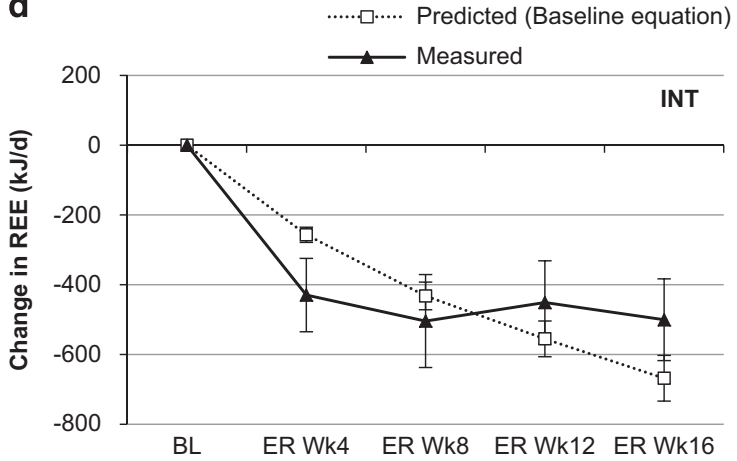

f

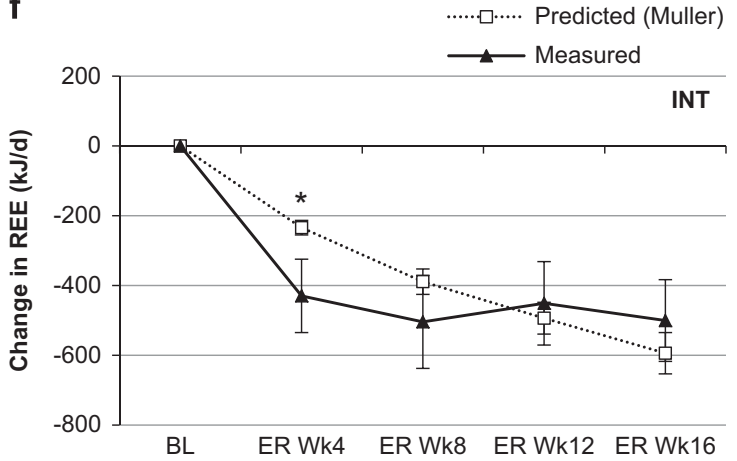

Figure 3. Change from baseline in resting energy expenditure (REE; $\mathrm{kJ} \mathrm{d}^{-1}$ ) for the continuous (CON; $\left.N=19\right)$ and intermittent (INT; $\left.N=17\right)$ groups. Data are mean \pm s.e.m. (a) Change in absolute (unadjusted) REE after each 4 weeks of ER for the CON and INT groups. *Significant difference between groups; $P<0.05$. (b) Change in REE adjusted for FFM and FM after each 4 weeks of ER in CON and INT groups. *Significant difference between groups; $P<0.05$. (c) Change in predicted REE (from baseline regression equation) and measured REE at 4,8 , 12 and 16 weeks of ER for the CON group. *Significant difference between predicted and measured; $P<0.05$. (d) Change in predicted REE (from baseline regression equation) and measured REE at 4, 8, 12 and 16 weeks of ER for the INT group. *Significant difference between predicted and measured; $P<0.05$. (e) Change in predicted REE (from Muller et al. ${ }^{37}$ equation) and measured REE at $4,8,12$ and 16 weeks of ER for the CON group. *Significant difference between predicted and measured; $P<0.05$. (f) Change in predicted REE (from Muller et al. ${ }^{37}$ equation) and measured REE at 4, 8, 12 and 16 weeks of ER for the INT group. ${ }^{*}$ Significant difference between predicted and measured; $P<0.05$.

but these findings are broadly consistent with the work of Jebb et $a l^{41}$ who reported no change REE/kgFFM following an 18-week intervention consisting of repeated cycles of 2 weeks of a very low energy diet alternating with 4 weeks of ad libitum intake. However, a continuous comparison group was not investigated in that study, and participants regained weight during the ad libitum periods such that the $\sim 10.7 \mathrm{~kg}$ lost during ER periods was reduced to $5.9 \mathrm{~kg}$ over the entire intervention. Importantly, in the present study, the preservation of REE during ER in the INT group was achieved without compromising weight loss.

Weight regain following successful weight loss through dietary intervention is common, and for decades there has been a concerted effort to find strategies to prevent recidivism. ${ }^{52}$ Followup data were only available for a subsample in the present study, although these participants did not differ appreciably from the total cohort at baseline, nor in their magnitude of response to the intervention. While both the CON and INT groups regained weight over the 6-month follow-up, the smaller (albeit non-significantly smaller) regain in the INT vs CON group resulted in a widening of the difference in weight loss between groups from $\sim 5 \mathrm{~kg}$ at Wk16ER to $\sim 8 \mathrm{~kg}$ at the 6-month follow-up. Indeed, weight at follow-up was not significantly different from weight at the end of baseline in the CON group (signifying almost complete weight regain), whereas it remained significantly reduced relative to baseline in the INT group. This suggests that the intermittent approach employed in this study may have benefits over continuous ER that extend beyond the period of active ER. Further, the guidelines from the National Health and Medical Research Council of Australia, ${ }^{53}$ in line with other health organisations around the world, recommend that adults with 

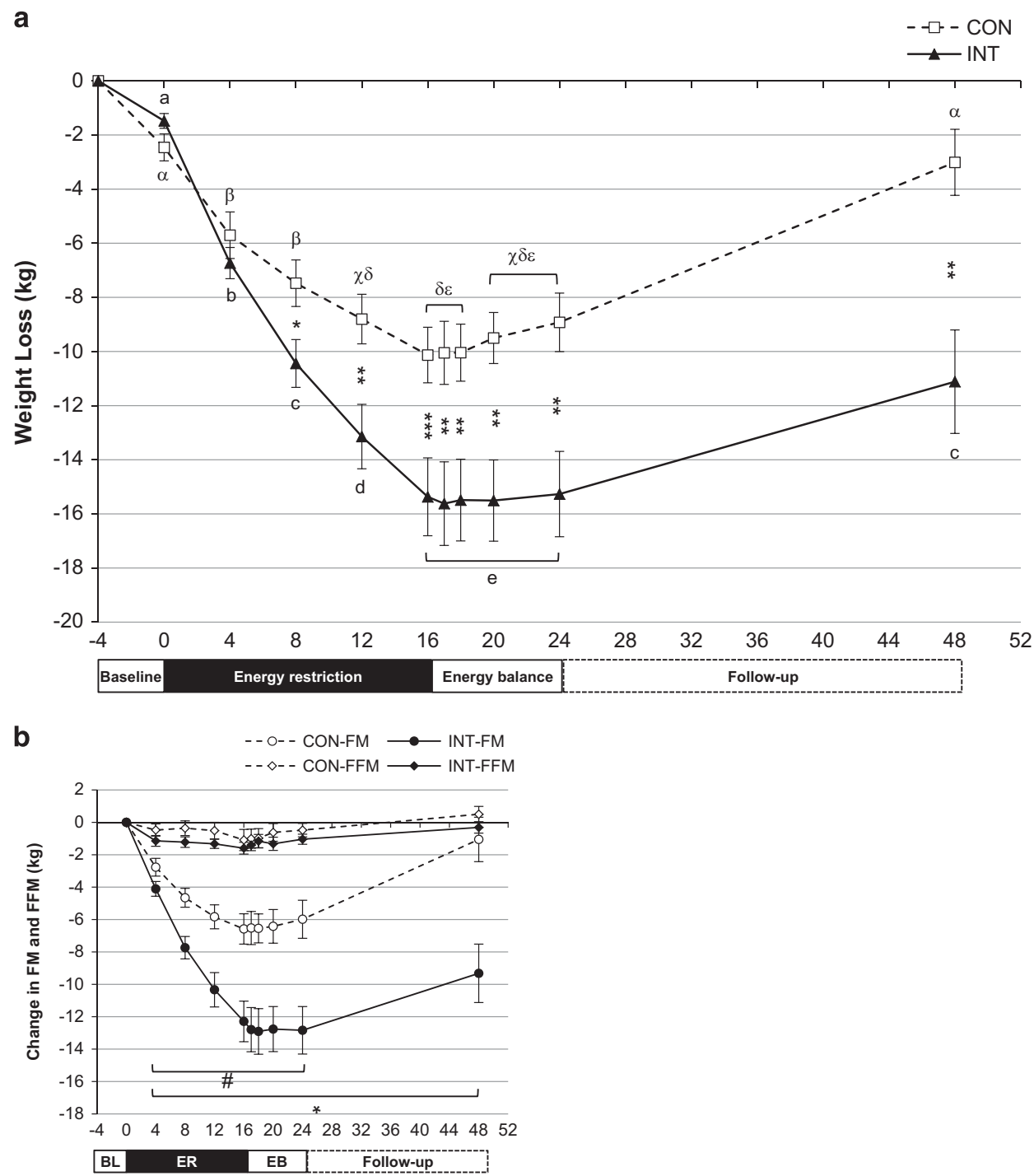

Figure 4. Weight and body composition in the subsample (CON: $N=13$, INT: $N=15$ ) of participants with data at all the following time points: baseline, during and end of energy restriction (ER), during and after 8 weeks of energy balance immediately post-ER-intervention, and followup 6 months later. (a) Weight loss (kg; mean \pm s.e.m.). Significant difference between groups $* P<0.05, * * P<0.01, * * * P<0.001$. Different letters indicate significant differences between time points within each group $(P<0.05 ;$ CON: $\alpha, \beta, \chi, \delta, \varepsilon ;$ INT: a,b,c,d,e). (b) Changes in FFM and FM (kg; mean \pm s.e.m.). \# FM significantly different from baseline in CON; * FM significantly different from baseline in INT $(P<0.05)$. Note: $N=13$ for CON, except $N=12$ for Wk1 and Wk2 of EB (Weeks 17 and 18) and $N=15$ for INT, except $N=14$ for Wk1, 2, 4 and 8 of EB (Weeks 17 , 18,20 and 24).

overweight or obesity should aim to lose $5 \%$ of initial weight as this can result in significant health benefits. To achieve this level of weight loss it took, on average, 8 weeks of continuous, but only 4 weeks of intermittent ER. Furthermore, at the 6-month follow-up, only the INT group had an average weight loss above this $5 \%$ threshold.

A strength of this study was the tight control of dietary prescription and food provision which ensured that the CON and INT groups received the same 'dose' of ER by: (1) matching energy deficit over the 16 weeks of restriction, and (2) achieving weight stability in the intervening energy balance blocks in the INT group. A further strength of this study is that it used the 2:2-week intermittent model, which was designed based on empirical evidence of the time course of adaptation to changes in energy intake, as a framework to investigate the mechanisms underlying any differences in weight loss between groups. In contrast, most studies comparing intermittent and continuous ER have been designed only to determine whether various forms of intermittent ER produce superior weight loss. This study also has several limitations. Firstly, as a very demanding study for participants, there was some attrition (Supplementary Item 3). However, it did not differ appreciably between groups, and was comparable to other studies using intermittent ER. ${ }^{47,52,54}$ Furthermore, although higher retention would have increased statistical power, we have shown from completers and ITT analyses that the main findings remained significant despite attrition. A second limitation was the small weight loss in the 4-week baseline phase. We can only speculate that the small weight loss was an acute response to changes in diet composition. Despite this, we are confident that our determination of energy requirements was robust for three reasons: (1) weight stability was achieved in the INT group during the seven energy balance blocks; (2) weight change over the 4week baseline phase in the combined cohort was lower than has been reported in other free-living studies where energy requirements were calculated from published REE equations; ${ }^{55}$ and (3) weight change in the last 2 weeks of baseline was comparable to that reported in a recent study in which participants were admitted to a metabolic ward with energy requirements 
determined from metabolic chamber measurements. ${ }^{56} \mathrm{~A}$ third limitation was that we did not measure REE and body composition during energy balance blocks in the INT group. We are currently undertaking a follow-up study (Australian New Zealand Clinical Trials Registry ref: ACTRN12615000116527) including these measurements in both ER and energy balance blocks to provide more detailed information about the effects of repeated cycles of ER and energy balance. While not a limitation, it is also important to acknowledge that we cannot determine from the present data whether 2 weeks is the optimal duration for ER and energy balance blocks, only that this intervention resulted in more effective weight loss than continuous ER. Indeed, it may be useful to investigate different durations and ratios of ER to energy balance, given the recent findings of Muller et al., ${ }^{26}$ suggesting adaptive thermogenesis may be completely manifest within just one week of ER.

In conclusion, intermittent ER, delivered as alternating 2-week blocks of ER and energy balance, resulted in greater weight loss (fat loss) without greater loss of FFM, attenuation of the reduction in REE, and superior weight loss retention after 6 months, compared with an equivalent 'dose' of continuous ER. While adaptive reductions in REE were attenuated using this 2:2 intermittent ER approach, it is possible that greater weight loss in the INT group may also be due to reduced compensation in other energetic functions such as the thermic effect of food and activity energy expenditure. Additionally, there is the need to investigate the effectiveness of this dietary approach when individuals are not provided meals in a tightly controlled metabolic study. Therefore, while additional work is needed to further investigate the mechanistic bases for this novel intermittent approach, these findings provide preliminary support for the model as a superior alternative to continuous ER.

\section{CONFLICT OF INTEREST}

Amanda Sainsbury has received payment from Eli Lilly, the Pharmacy Guild of Australia, Novo Nordisk, the Dietitians Association of Australia, Shoalhaven Family Medical Centres, and the Pharmaceutical Society of Australia for seminar presentation at conferences, and has served on the Nestlé Health Science OptifastVLCD Advisory Board since 2016. She is also the author of The Don't go Hungry Diet (Bantam, Australia and New Zealand, 2007) and Don't go Hungry for Life (Bantam, Australia and New Zealand, 2011). The remaining authors declare no conflict of interest.

\section{ACKNOWLEDGEMENTS}

This project and salary for REW was funded by an Australian National Health and Medical Research Council (NHMRC) project grant (497223). AS was supported by NHMRC Fellowships (481355 and 1042555). The authors sincerely thank the efforts of Ainsley Groves, Alicia Fuchs, Connie Wishart, and Leonie Ruddick-Collins for their assistance, and the participants for their commitment during the study.

\section{AUTHOR CONTRIBUTIONS}

NMB led the drafting of the manuscript. NMB, AS, APH, NAK conceived of the study and obtained funding. REW coordinated the study, and with NMB and $\mathrm{APH}$ arranged study protocols. All authors participated in the design of the study protocols, helped to draft the manuscript, read and approved the final manuscript.

\section{REFERENCES}

1 Byrne NM, Hills AP. Biology or behavior: which is the strongest contributor to weight gain? Curr Obes Rep 2013; 2: 65-76.

2 King NA, Horner K, Hills AP, Byrne NM, Wood RE, Bryant E et al. Exercise, appetite and weight management: understanding the compensatory responses in eating behaviour and how they contribute to variability in exercise-induced weight loss. Brit J Sport Med 2012; 46: 315.

3 Ahima RS, Prabakaran D, Mantzoros C, Qu D, Lowell B, Maratos-Flier E et al. Role of leptin in the neuroendocrine response to fasting. Nature 1996; 382: 250-225.
4 Erickson JC, Ahima RS, Hollopeter G, Flier JS, Palmiter RD. Endocrine function of neuropeptide Y knockout mice. Regul Pept 1997; 70: 199-202.

5 Friedl KE, Moore RJ, Hoyt RW, Marchitelli LJ, Martinez-Lopez LE, Askew EW. Endocrine markers of semistarvation in healthy lean men in a multistressor environment. J Appl Physiol 2000; 88: 1820-1830.

6 Doucet E, Imbeault P, St-Pierre S, Almeras N, Mauriege P, Richard D et al. Appetite after weight loss by energy restriction and a low-fat diet-exercise follow-up. Int J Obes Relat Metab Disord 2000; 24: 906-914.

7 Niskanen L, Laaksonen DE, Punnonen K, Mustajoki P, Kaukua J, Rissanen A. Changes in sex hormone-binding globulin and testosterone during weight loss and weight maintenance in abdominally obese men with the metabolic syndrome. Diabetes Obes Metab 2004; 6: 208-215.

8 Rosenbaum M, Hirsch J, Murphy E, Leibel RL. Effects of changes in body weight on carbohydrate metabolism, catecholamine excretion, and thyroid function. Am J Clin Nutr 2000; 71: 1421-1432.

9 Seimon RV, Roekenes JA, Zibellini J, Zhu B, Gibson AA, Hills AP et al. Do intermittent diets provide physiological benefits over continuous diets for weight loss? A systematic review of clinical trials. Mol Cell Endocrinol 2015; 418 (Pt 2): 153-172.

10 Dulloo AG, Jacquet J, Montani JP, Schutz Y. Adaptive thermogenesis in human body weight regulation: more of a concept than a measurable entity? Obes Rev 2012; 13 (Suppl 2): 105-121.

11 Byrne NM, Wood RE, Schutz Y, Hills AP. Does metabolic compensation explain the majority of less-than-expected weight loss in obese adults during a short-term severe diet and exercise intervention? Int J Obes (Lond) 2012; 36: 1472-1478.

12 Alpert SS. A two-reservoir energy model of the human body. Am J Clin Nutr 1979; 32: $1710-1718$.

13 Bray GA. Effect of caloric restriction on energy expenditure in obese patients. Lancet 1969; 2: 397-398.

14 Bessard T, Schutz Y, Jequier E. Energy expenditure and postprandial thermogenesis in obese women before and after weight loss. Am J Clin Nutr 1983; 38: 680-693.

15 Elliot DL, Goldberg L, Kuehl KS, Bennett WM. Sustained depression of the resting metabolic rate after massive weight loss. Am J Clin Nutr 1989; 49: 93-96.

16 Geissler CA, Miller DS, Shah M. The daily metabolic rate of the post-obese and the lean. Am J Clin Nutr 1987; 45: 914-920.

17 Leibel RL, Hirsch J. Diminished energy requirements in reduced-obese patients. Metabolism 1984; 33: 164-170.

18 Leibel RL, Rosenbaum M, Hirsch J. Changes in energy expenditure resulting from altered body weight. N Engl J Med 1995; 332: 621-628.

19 Valtuena S, Blanch S, Barenys M, Sola R, Salas-Salvado J. Changes in body composition and resting energy expenditure after rapid weight loss: is there an energy-metabolism adaptation in obese patients? Int J Obes Relat Metab Disord 1995; 19: 119-125.

20 Byrne NM, Weinsier RL, Hunter GR, Desmond R, PattersonMA, Darnell BE et al. Influence of distribution of lean body mass on resting metabolic rate after weight loss and weight regain: comparison of responses in white and black women. Am J Clin Nutr 2003; 77: 1368-1373.

21 Smith DJ. A framework for understanding the training process leading to elite performance. Sports Med 2003; 33: 1103-1126.

22 Grande F, Anderson JT, Keys A. Changes of basal metabolic rate in man in semistarvation and refeeding. J Appl Physiol 1958; 12: 230-238.

23 Keys A, Brozek J, Henschel A, Mickelson O, Taylor H. The Biology of Human Starvation. University of Minnesota Press: Minneapolis, 1950.

24 Capel F, Viguerie N, Vega N, Dejean S, Arner P, Klimcakova E et al. Contribution of energy restriction and macronutrient composition to changes in adipose tissue gene expression during dietary weight-loss programs in obese women. J Clin Endocrinol Metab 2008; 93: 4315-4322.

25 Franck N, Gummesson A, Jernas M, Glad C, Svensson PA, Guillot G et al. Identification of adipocyte genes regulated by caloric intake. J Clin Endocrinol Metab 2011; 96: E413-E418.

26 Muller MJ, Enderle J, Pourhassan M, Braun W, Eggeling B, Lagerpusch M et al. Metabolic adaptation to caloric restriction and subsequent refeeding: the Minnesota Starvation Experiment revisited. Am J Clin Nutr 2015; 102: 807-819.

27 James WP, Shetty PS. Metabolic adaptation and energy requirements in developing countries. Hum Nutr-Clin Nutr 1982; 36: 331-336.

28 Rickman AD, Williamson DA, Martin CK, Gilhooly CH, Stein Rl, Bales CW et al. The CALERIE Study: design and methods of an innovative $25 \%$ caloric restriction intervention. Contemp Clin Trials 2011; 32: 874-881.

29 Weir JB. New methods for calculating metabolic rate with special reference to protein metabolism. J Physiol 1949; 109: 1-9.

30 Allison DB, Paultre F, Goran MI, Poehlman ET, Heymsfield SB. Statistical considerations regarding the use of ratios to adjust data. Int $J$ Obes Relat Metab Disord 1995; 19: 644-652.

31 Brozek J, Grande F. Body composition and basal metabolism in man: correlation analysis versus physiological approach. Hum Biol 1955; 27: 22-31. 
32 Galgani JE, Santos JL. Insights about weight loss-induced metabolic adaptation. Obesity (Silver Spring) 2016; 24: 277-278.

33 Hall KD, Kerns JC, Brychta R, Knuth ND. Response to "Overstated metabolic adaptation after 'The Biggest Loser' intervention”. Obesity (Silver Spring) 2016; 24: 2026.

34 Heymsfield SB, Thomas D, Bosy-Westphal A, Shen W, Peterson CM, Muller MJ. Evolving concepts on adjusting human resting energy expenditure measurements for body size. Obes Rev 2012; 13: 1001-1014.

35 Kuchnia A, Huizenga R, Frankenfield D, Matthie JR, Earthman CP. Overstated metabolic adaptation after "the biggest loser" intervention. Obesity 2016; 24: 2025.

36 Muller MJ, Enderle J, Bosy-Westphal A. Changes in energy expenditure with weight gain and weight loss in humans. Curr Obes Rep 2016; 5: 413-423.

37 Muller MJ, Wang Z, Heymsfield SB, Schautz B, Bosy-Westphal A. Advances in the understanding of specific metabolic rates of major organs and tissues in humans. Curr Opin Clin Nutr Metab Care 2013; 16: 501-508.

38 Weinsier RL, Schutz Y, Bracco D. Reexamination of the relationship of resting metabolic rate to fat-free mass and to the metabolically active components of fatfree mass in humans. Am J Clin Nutr 1992; 55: 790-794.

39 Muller MJ, Bosy-Westphal A, Klaus S, Kreymann G, Luhrmann PM, NeuhauserBerthold $\mathrm{M}$ et al. World Health Organization equations have shortcomings for predicting resting energy expenditure in persons from a modern, affluent population: generation of a new reference standard from a retrospective analysis of a German database of resting energy expenditure. Am J Clin Nutr 2004; 80: 1379-1390.

40 Gupta SK. Intention-to-treat concept: a review. Perspect Clin Res 2011; 2: 109-112.

41 Jebb SA, Goldberg GR, Coward WA, Murgatroyd PR, Prentice AM. Effects of weight cycling caused by intermittent dieting on metabolic rate and body composition in obese women. Int J Obes 1991; 15: 367-374.

42 Trepanowski JF, Kroeger CM, Barnosky A, Klempel MC, Bhutani S, Hoddy KK et al. Effect of alternate-day fasting on weight loss, weight maintenance, and cardioprotection among metabolically healthy obese adults: a randomized clinical trial. JAMA Int Med 2017; 177: 930-938.

43 Harvie $M$, Howell A. Potential benefits and harms of intermittent energy restriction and intermittent fasting amongst obese, overweight and normal weight subjects-a narrative review of human and animal evidence. Behav Sci 2017; 7: 4.

44 Headland M, Clifton PM, Carter S, Keogh JB. Weight-loss outcomes: a systematic review and meta-analysis of intermittent energy restriction trials lasting a minimum of 6 months. Nutrients 2016; 8: 354. e-pub ahead of print 8 June 2016; doi:10.3390/nu8060354.

45 Heilbronn LK, Smith SR, Martin CK, Anton SD, Ravussin E. Alternate-day fasting in nonobese subjects: effects on body weight, body composition, and energy metabolism. Am J Clin Nutr 2005; 81: 69-73.

46 Arguin H, Dionne IJ, Sénéchal M, Bouchard DR, Carpentier AC, Ardilouze J-L et al. Short- and long-term effects of continuous versus intermittent restrictive diet approaches on body composition and the metabolic profile in overweight and obese postmenopausal women: a pilot study. Menopause 2012; 19: 870-876.

47 Keogh JB, Pedersen E, Petersen KS, Clifton PM. Effects of intermittent compared to continuous energy restriction on short-term weight loss and long-term weight loss maintenance: Intermittent compared to continuous diet. Clin Obes 2014; 4: 150-156.

48 Wing RR, Jeffery RW. Prescribed "breaks" as a means to disrupt weight control efforts. Obes Res 2003; 11: 287-291.

49 Dulloo AG, Jacquet J, Montani JP, Schutz Y. How dieting makes the lean fatter: from a perspective of body composition autoregulation through adipostats and proteinstats awaiting discovery. Obes Rev 2015; 16: 25-35.

50 Hill JO, Schlundt DG, Sbrocco T, Sharp T, Pope-Cordle J, Stetson B et al. Evaluation of an alternating-calorie diet with and without exercise in the treatment of obesity. Am J Clin Nutr 1989; 50: 248-254.

51 Wing RR, Blair E, Marcus M, Epstein LH, Harvey J. Year-long weight loss treatment for obese patients with type II diabetes: does including an intermittent very-lowcalorie diet improve outcome? Am J Med 1994; 97: 354-362.

52 Harvie M, Wright C, Pegington M, McMullan D, Mitchell E, Martin B et al. The effect of intermittent energy and carbohydrate restriction $\mathrm{v}$. daily energy restriction on weight loss and metabolic disease risk markers in overweight women. $\mathrm{Br} J \mathrm{Nutr}$ 2013; FirstView: 1-14.

53 National Health and Medical Research Council. Clinical Practice Guidelines for the Management of Overweight and Obesity in Adults, Adolescents and Children in Australia, 2013. Melbourne: National Health and Medical Research Council; 2013.

54 Hoddy KK, Gibbons C, Kroeger CM, Trepanowski JF, Barnosky A, Bhutani S et al. Changes in hunger and fullness in relation to gut peptides before and after 8 weeks of alternate day fasting. Clin Nutr 2016; 35: 1380-1385.

55 Klempel MC, Kroeger CM, Varady KA. Alternate day fasting increases LDL particle size independently of dietary fat content in obese humans. Eur J Clin Nutr 2013; 67: 783-785.

56 Hall KD, Chen KY, Guo J, Lam YY, Leibel RL, Mayer LE et al. Energy expenditure and body composition changes after an isocaloric ketogenic diet in overweight and obese men. Am J Clin Nutr 2016; 104: 324-333.

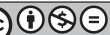

This work is licensed under a Creative Commons AttributionNonCommercial-NoDerivs 4.0 International License. The images or other third party material in this article are included in the article's Creative Commons license, unless indicated otherwise in the credit line; if the material is not included under the Creative Commons license, users will need to obtain permission from the license holder to reproduce the material. To view a copy of this license, visit http:// creativecommons.org/licenses/by-nc-nd/4.0/

(c) The Author(s) 2018

Supplementary Information accompanies this paper on International Journal of Obesity website (http://www.nature.com/ijo) 